\title{
Assessing Employee Wellbeing in Schools Using a Multifaceted Approach: Associations with Physical Health, Life Satisfaction, and Professional Thriving
}

\author{
Margaret L. Kern ${ }^{1 *}$, Lea Waters ${ }^{2}$, Alejandro Adler ${ }^{1}$, Mathew White ${ }^{2,3}$ \\ ${ }^{1}$ Department of Psychology, University of Pennsylvania, Philadelphia, USA \\ ${ }^{2}$ Melbourne Graduate School of Education, University of Melbourne, Melbourne, Australia \\ ${ }^{3}$ St. Peter's College, Adelaide, Australia \\ Email: *mkern@sas.upenn.edu
}

Received 20 February 2014; revised 21 March 2014; accepted 15 April 2014

Copyright (C) 2014 by authors and Scientific Research Publishing Inc.

This work is licensed under the Creative Commons Attribution International License (CC BY). http://creativecommons.org/licenses/by/4.0/

(c) (i) Open Access

\begin{abstract}
Purpose: Drawing on recent advances in the field of positive psychology, we conducted a pilot evaluation of employee wellbeing using Seligman's (2011) multidimensional PERMA (positive emotion, engagement, relationships, meaning, and accomplishment) model of flourishing. We analyzed associations between multiple aspects of employee wellbeing and three outcomes: physical health, life satisfaction, and professional thriving. Method: Employees $(N=153)$ from a large private school in Australia completed a survey with items theoretically relevant to the PERMA theory. Factor analyses recovered the expected five PERMA components and a negative emotion factor. Regression analyses estimated cross-sectional associations between the wellbeing factors and self-reported physical health, life satisfaction, and professional thriving (job satisfaction and organizational commitment). Results: Differential associations support the multidimensional approach to defining and measuring wellbeing. For example, staff with higher engagement and better relationships reported greater job satisfaction and organizational commitment. Conclusions: Multidimensional wellbeing assessments can help school administrators understand and improve staff wellbeing, supporting policy and practice designs that ultimately will promote wellness for all stakeholders in the education system.
\end{abstract}

\section{Keywords}

Wellbeing, Positive Psychology, Measurement, Psychosocial Context, Positive Education

\footnotetext{
*Corresponding author.
}

How to cite this paper: Kern, M. L., et al. (2014). Assessing Employee Wellbeing in Schools Using a Multifaceted Approach: Associations with Physical Health, Life Satisfaction, and Professional Thriving. Psychology, 5, 500-513. 


\section{Introduction}

Positive psychology (PP) is a scientific field that studies the optimal functioning of individuals, groups, and institutions (Gable \& Haidt, 2005). Since its inception, the field has grown rapidly, with a large volume of peer reviewed publications and an expanding reach beyond the field of psychology to disciplines such as education and organizational behavior (Rusk \& Waters, 2013). The current pilot study examines the relation between employee wellbeing, physical health, life satisfaction, and professional thriving (job satisfaction and organizational commitment) in school staff. Specifically, we approach employee wellbeing from a positive psychology framework, adopting Seligman's (2011) multidimensional PERMA model of flourishing, in which wellbeing is defined in terms of five domains: positive emotions, engagement, relationships, meaning, and accomplishment.

Teacher wellbeing has been a longstanding topic of research interest. However, studies have primarily focused on problems faced by employees and illbeing, more so than it has focused on employee strengths and wellbeing (Calabrese, Hester, Friesen, \& Burkhalter, 2010; Hoy \& Tarter, 2011). For example, three decades of research has been devoted to the study of teacher stress (Chaplain, 2008; Howard \& Johnson, 2004). Other prominent topics of study related to teacher wellbeing include anxiety, depression, frustration, and burnout (e.g., Chan, 2011; Kyriacou 2001).

Although studying teacher illbeing has been informative, it has not given us a comprehensive understanding of teacher wellbeing. Indeed, a positive psychology approach suggests that mental health ranges from extremely negative to extremely positive (Huppert \& So, 2013; Keyes, 2002). The traditional approach of measuring teacher wellbeing from a problem-based standpoint (e.g., reducing teacher stress or job dissatisfaction) has ignored the positive end of this spectrum. Positive functioning is not simply surviving stress; it also entails thriving physically, mentally, socially, and professionally. Clearly, negative outcomes should be monitored and reduced. However, Peterson and Park (2003) aptly note, "if our interest is in the good life, we must look explicitly at indices of human thriving” (p. 144). Hoy and Tarter (2011) argue that positive psychology can provide a "fresh lens" through which educational staff wellbeing can be built. Similarly, Duckworth, Quinn and Seligman (2009) suggest that "positive traits that buffer against adversity might contribute to teacher effectiveness" (p. 540).

Beyond positive versus negative sides of mental health, positive psychologists have recently attempted to better delineate the theoretical framework of wellbeing. Several theorists have argued that wellbeing is best characterized as a profile of indicators across multiple domains (Forgeard, Jayawickreme, Kern, \& Seligman, 2011; Stiglitz, Sen, \& Fitoussi, 2009). For example, as noted above, Seligman (2011) suggests five components. Similarly, Ryff and Keyes (1995) suggest six domains and Huppert and So (2013) include 10 flourishing items.

In this paper, we build upon Seligman's (2011) PERMA model as an organizing framework for measuring workplace wellbeing. The field of positive organizational scholarship has placed strong emphasis on the research and application of employee wellbeing (Cameron, 2003; Dutton, \& Sonenshein, 2007), and we draw this literature into the PERMA model. Positive and negative emotions are included in every major model and measure of subjective wellbeing, and range from negative to positive and from low arousal (e.g., relaxed, calm) to high arousal (e.g., excited, enthusiastic). Although the PERMA model focuses on positive emotion, we also include negative emotion to capture both positive and negative sides of the mental health spectrum. Work engagement is characterized by vigor toward tasks, dedication to the work and organization, and absorption (Schaufeli, Salanova, González-Romá, \& Bakker, 2002). Engagement is an area of prime interest for educational administration and organizational psychology, as it is seen as the antithesis of burnout. Cameron and colleagues’ (2011) organizational virtue model, which includes positive workplace practices such as caring, compassionate support, forgiveness, and respect, speaks to coworker relationships and the interpersonal culture of a workplace as a whole. Since the 1960s, research has suggested that people function best in both personal and work lives when they have a sense of meaning or purpose, defined in terms of having a direction, connecting to something larger than oneself, and feeling that what one does is valuable (Steger, 2012). Finally, accomplishment is often objectively defined in terms of awards, earnings, and prestige, but also entails a subjective feeling of mastery and daily achievement, which we focus on here.

In this pilot study, we explore the PERMA framework in relation to three employee outcomes: physical health, life satisfaction, and professional thriving, assessed in terms of subjective job satisfaction and organizational commitment. Numerous reviews and meta-analyses indicate that wellbeing, broadly construed, relates to posi- 
tive physical, life, and professional outcomes (e.g., Cotton \& Hart, 2003; Cropanzano \& Wright, 2001; Howell, Kern, \& Lyubomirsky, 2007; Judge, Thoresen, Bono, \& Patton, 2001; Lyubomirsky, King, \& Diener, 2005; Wright \& Cropanzano, 2004). Prior research has generally lumped wellbeing constructs together, but there is some indication that different aspects of wellbeing relate distinctly to outcomes. For example, a review of positive psychological wellbeing and cardiovascular disease suggested that optimism and emotional vitality related to lower disease risk, whereas positive emotion did not (Boehm \& Kubzansky, in press). Studies have reliably found different associations for negative versus positive variables, but Diener and Chan (2011) explicitly noted that different types of wellbeing "have not been clearly differentiated or measured in most research" (p. 26), making it impossible to know what is most beneficial for health and other outcomes.

The aim of this study was to investigate the effects of a multidimensional measure of educational staff wellbeing on physical health, life satisfaction, job satisfaction, and organizational commitment. Applying a multidimensional model of wellbeing such as the PERMA model is important for understanding which aspects of wellbeing are most relevant for different outcomes. To date, there has been no study that has simultaneously tested all five elements of PERMA in employees. Due to the lack of differentiation in existing literature, the unique contribution of each PERMA component is unknown. Thus, we did not make specific hypotheses about the exact pattern of associations between the PERMA factors and health, life, and job outcomes, but begin to build the foundation for such differentiated perspectives. More specifically, using PERMA as a measurement framework, the study was guided by two exploratory research questions:

1) Does wellbeing add predictive variance to physical health, life satisfaction, job satisfaction, and organizational commitment, beyond the effect of negative emotion?

2) Are the PERMA factors differentially related to staff outcomes? Are some aspects of PERMA more strongly related to professional outcomes (job satisfaction and organizational commitment) compared to nonwork outcomes (physical health and life satisfaction)?

\section{Method}

\subsection{Participants}

Employees at St Peter's College, Adelaide, Australia were invited by email to complete an anonymous online assessment using Survey Monkey software. Responses were received from 153 staff members, with 148 complete responses (73 male, 74 female, 6 unknown).Sixty percent of the participants were teaching staff (i.e., junior and senior school teachers) and $40 \%$ were non-teaching teaching (e.g., administrative staff, information technology staff, grounds staff, catering staff). The average length of tenure at the school was seven years, and the age range was 28 to 65 years old.

\subsection{Measures}

The current study used data from a larger study of students and staff, which included an extensive staff survey. The survey included numerous items, scales, and measures relevant to the PERMA constructs. For the current study, we selected four existing scales and several additional items that theoretically aligned with the five PERMA components. Scales included 20 emotions from the Positive and Negative Affect Schedule (PANAS; Watson, Clark, \& Tellegen, 1988); the 17-item Utrecht Work Engagement Scale (Schaufeli et al., 2002); the 29-item Organizational Virtuousness Scale (Cameron et al., 2011); the presence of meaning subscale from the Meaning in Life Questionnaire (Steger, Frazier, Oishi, \& Kaler, 2006); and 10 miscellaneous items relevant to subjective accomplishment (see Appendix for full item set).

For outcomes, we included measures of physical health, life satisfaction, job satisfaction, and organizational commitment. Participants rated their self-perceived health and physical vitality (6 items, $\alpha=.80$ ), and somatic symptoms (7 items, $\alpha=.66$ ). Life satisfaction was assessed with the five-item Satisfaction with Life Scale ( $\alpha$ = .89; Diener, Emmons, Larsen, \& Griffin, 1985). Job satisfaction was assessed through four items from the Index of Job Satisfaction ( $\alpha=.89$; Brayfield \& Rothe, 1951). Organizational commitment was assessed through the Organizational Commitment Scale (9 items, $\alpha=.88$; Mowday, Steers, \& Porter, 1979). Higher values indicate more of eachoutcome (i.e., greater vitality, more somatic symptoms, higher life or job satisfaction, greater organizational commitment). 


\section{Results}

\subsection{Establishing a Multidimensional Wellbeing Measurement Model}

First, we used exploratory and confirmatory factor analyses to examine whether the five PERMA factors were present. Before beginning analysis, we randomly split the sample into two sets: a development set $(n=75)$ to create the factor model, and a test set $(n=78)$ to test the structure.

We began with the development set. As we had a limited sample size, we first reduced the number of items entering the factor model for each domain. For emotion, an exploratory principle components analysis with oblimin rotation $(\Delta=0)$ with the 20 PANAS items indicated two clear factors: positive and negative emotion. We retained the six highest loading items on each factor (positive emotion: $\alpha=.88$; negative emotion: $\alpha=.89$ ). We extracted the first principle component factors and retained the six highest loading items from the 17-item Ultrecht Work Engagement Scale for engagement $(\alpha=.89)$ and from the 29 items from the Organizational Virtuousness Scale for relationships $(\alpha=.97)$. We retained all five items from the presence of meaning subscale of the Meaning in Life Questionnaire $(\alpha=.89)$. For accomplishment, we extracted the first principle component factor from 10 miscellaneous survey items (see Appendix), and retained the highest seven items $(\alpha=.86)^{1}$.

Through this process, we reduced the number of items entering the combined factor analysis to 36 items and six factors (Positive emotion: 6 items, Engagement: 6 items, Relationships: 6 items, Meaning: 5 items, Accomplishment: 7 items, Negative emotion: 6 items). We then performed a principal components analysis with direct oblimin rotation with the 36 items. The Kaiser criterion (Eigenvalues < 1.00), scree plot, and Velicer's (1976) minimal average partial (MAP) test all indicated a six-factor solution, and items loaded on the expected factors.

Using the test set, we then examined the final factor structure with a confirmatory factor analysis using the lavaan package (version .5 - 12, Rosseel, 2012) in R (version 2.15.2). Model fit was evaluated using the root mean square error of approximation (RMSEA), the Standardized Root Mean Residual (SRMR), the Comparative Fit Index (CFI) and the Tucker Lewis Index (TLI). The model exhibited acceptable fit to the data (RMSEA $=.07,90 \%$ confidence interval $[\mathrm{CI}]=.06, .09]$, SRMR $=.08, \mathrm{CFI}=.87, \mathrm{TLI}=.86)^{2}$. Finally, we combined the development and test samples and estimated a final factor model, which demonstrated good fit to the data $(\mathrm{RMSEA}=.06[90 \% \mathrm{CI}=.05, .06], \mathrm{SRMR}=.06, \mathrm{CFI}=.93, \mathrm{TLI}=.92)$. Final items, latent factor loadings, and factor reliabilities in the full sample are summarized in Table 1 . The items were averaged to create composite wellbeing factors.

\subsection{Associations with Health, Life, and Work Outcomes}

With the wellbeing factors established, we then tested cross-sectional associations with five outcomes: health/ vitality, somatic symptoms, life satisfaction, job satisfaction, and organizational commitment. Descriptives and variable correlations with the wellbeing factors are summarized in Table 2. The wellbeing components were significantly related (positively for the five PERMA domains; negatively for negative emotion) to health (health/ vitality), life (life satisfaction), and job (job satisfaction, organizational commitment) outcomes, with inverse associations for somatic symptoms. Positive emotion, meaning, and accomplishment were most strongly related to health and life satisfaction, whereas engagement and relationships related most strongly to job satisfaction and organizational commitment.

We then examined the unique prediction of each factor using hierarchical linear regression with simultaneous entry, predicting each outcome from the wellbeing factors and controlling for gender. Results are summarized in Table 3. The wellbeing factors were most relevant to job and life outcomes, explaining $58.6 \%$ of the variance in job satisfaction, $40.6 \%$ of the variance in organizational commitment, and $42.3 \%$ of the variance in life satisfaction. Meaning was the strongest predictor of life satisfaction, workplace engagement and coworker relationships were most important for job satisfaction and commitment, and accomplishment was most important for health/ vitality. Negative emotions also remained significantly related to lower job and life satisfaction.

To demonstrate the added value of the profile approach to wellbeing compared to using a single number, Figure 1 compares the wellbeing profiles for staff members in the lowest quartile compared to the highest

\footnotetext{
${ }^{1}$ Six items provided high reliability while reducing the number of items overall. For accomplishment, an additional item substantially improved reliability and thus was retained.

${ }^{2}$ An RMSEA of .06 or lower and a SRMR of .09 or lower are considered acceptable; for the CFI and TLI, values above .90 are preferred (Hu $\&$ Bentler, 1999). However, with such a small sample, good fit would be hard to achieve.
} 
Table 1. Final items and latent factor loadings for the wellbeing factors.

\begin{tabular}{|c|c|c|}
\hline & Factor/item & $\lambda$ \\
\hline \multicolumn{3}{|c|}{ Positive Emotion } \\
\hline \multicolumn{3}{|c|}{ Determined } \\
\hline \multicolumn{3}{|c|}{ Interested } \\
\hline \multicolumn{3}{|c|}{ Enthusiastic } \\
\hline \multicolumn{3}{|l|}{ Inspired } \\
\hline \multicolumn{3}{|l|}{ Active } \\
\hline Alert & & . \\
\hline
\end{tabular}

Engagement

I am enthusiastic about my job.

I am proud on the work that I do.

I find the work that I do full of meaning and purpose.

My job inspires me.

At my work, I feel bursting with energy.

At my job I feel strong and vigorous.

Relationships

We provide emotional support to each other.

We show kindness to one another.

We genuinely care about each other.

We show compassion for each other.

We care for fellow employees who are struggling.

$\begin{array}{lr}\text { We build strong interpersonal relationships. } & .91\end{array}$ Meaning

My life has a clear sense of purpose. $\quad .90$

I have a good sense of what makes my life meaningful. $\quad .77$

I have discovered a satisfying life purpose. $\quad .84$

$\begin{array}{lr}\text { I understand my life’s meaning. } & .78\end{array}$

My life has no clear purpose. (Reversed) $\quad .68$

Accomplishment

$\begin{array}{ll}\text { I think I am doing pretty well. } & .68\end{array}$

How often do you feel you are making progress towards accomplishing your goals? 68

Most days I feel a sense of accomplishment from what I do. $\quad .69$

I am competent and capable in the activities that are important to me. .53

I am doing just as well as my peers.

I am competent and capable in my daily activities.

Most days I feel a sense of accomplishment from what I do. $\quad .73$

Negative Emotions

$\begin{array}{lr}\text { Afraid } & .83 \\ \text { Scared } & .78 \\ \text { Nervous } & .74 \\ \text { Distressed } & .70 \\ \text { Upset } & .62 \\ \text { Jittery } & .67\end{array}$


Table 2. Final wellbeing factors and outcome descriptives and correlations.

\begin{tabular}{|c|c|c|c|c|c|c|c|c|c|c|c|}
\hline Variable & $\mathrm{N}$ & Mean & SD & Min & Max & $\mathrm{P}$ & E & $\mathrm{R}$ & M & A & $\mathrm{N}$ \\
\hline Positive Emotion & 147 & 4.04 & 0.48 & 2.50 & 5.00 & 1.00 & & & & & \\
\hline Work Engagement & 148 & 3.12 & 0.48 & 1.17 & 4.00 & $.66^{* *}$ & 1.00 & & & & \\
\hline Coworker Relationships & 149 & 5.23 & 1.31 & 1.00 & 7.00 & $.34^{* *}$ & $.45^{* *}$ & 1.00 & & & \\
\hline Meaning & 147 & 5.60 & 0.93 & 3.00 & 7.00 & $.56^{* *}$ & $.46^{* *}$ & $.21^{*}$ & 1.00 & & \\
\hline Accomplishment & 151 & 3.78 & 0.71 & 1.00 & 4.99 & $.69^{* *}$ & $.68^{* *}$ & $.37^{* *}$ & $.57^{* *}$ & 1.00 & \\
\hline Negative Emotion & 147 & 2.25 & 0.61 & 1.00 & 4.17 & $-.29^{* *}$ & $-.41^{* *}$ & $-.28^{* *}$ & $-.28^{* *}$ & $-.51^{* *}$ & 1.00 \\
\hline Gender & 147 & 1.50 & 0.50 & 1.00 & 2.00 & -.16 & -.09 & -.16 & -.15 & -.12 & .004 \\
\hline Physical Health/ Vitality & 143 & 4.50 & 0.91 & 1.83 & 6.40 & $.42^{* *}$ & $.33^{* * *}$ & $.20^{*}$ & $.33^{* *}$ & $.47^{* *}$ & $-.26^{* *}$ \\
\hline Somatic Symptoms & 143 & 1.65 & 0.56 & 1.00 & 3.86 & $-.23^{* *}$ & $-.26^{* *}$ & -.13 & $-.22^{* *}$ & $-.25^{* *}$ & .13 \\
\hline Life Satisfaction & 147 & 3.72 & 0.71 & 1.00 & 5.00 & $.42^{* *}$ & $.33^{* *}$ & $.20^{*}$ & $.59^{* *}$ & $.51^{* *}$ & $-.39^{* *}$ \\
\hline Job Satisfaction & 148 & 4.03 & 0.70 & 1.00 & 5.00 & $.49^{* *}$ & $.71^{* *}$ & $.54^{* *}$ & $.39^{* *}$ & $.55^{* *}$ & $-.44^{* *}$ \\
\hline Organization Commitment & 146 & 3.96 & 0.64 & 1.67 & 5.00 & $.40^{* *}$ & $.55^{* *}$ & $.52^{* *}$ & $.30^{* *}$ & $.42^{* *}$ & $-.33^{* *}$ \\
\hline
\end{tabular}

Note: ${ }^{*} p<.05,{ }^{* *} p<.01$.

Table 3. Regression analyses predicting life, health, and job outcomes from the wellbeing factors.

\begin{tabular}{|c|c|c|c|c|c|c|c|}
\hline & $\beta$ & SE & $\mathrm{t}$ & & $\beta$ & SE & $\mathrm{t}$ \\
\hline Health/Vitality & & $R^{2}=.245^{* *}$ & & Job Satisfaction & & $R^{2}=.586^{* *}$ & \\
\hline Positive Emotion & 0.20 & 0.22 & 1.78 & Positive Emotion & -0.03 & 0.12 & -0.35 \\
\hline Work Engagement & -0.05 & 0.21 & -0.45 & Work Engagement & 0.49 & 0.12 & $6.02^{* *}$ \\
\hline Coworker Relations & 0.02 & 0.06 & 0.24 & Coworker Relations & 0.28 & 0.03 & $4.48^{* *}$ \\
\hline Meaning & 0.06 & 0.09 & 0.66 & Meaning & 0.06 & 0.05 & 0.84 \\
\hline Accomplishment & 0.31 & 0.16 & $2.50^{*}$ & Accomplishment & 0.05 & 0.09 & 0.49 \\
\hline Negative Emotion & -0.04 & 0.13 & -0.41 & Negative Emotion & -0.13 & 0.08 & $-1.99^{*}$ \\
\hline Gender & 0.03 & 0.14 & 0.44 & Gender & 0.05 & 0.08 & 0.82 \\
\hline Somatic Symptoms & & $R^{2}=.102^{*}$ & & Organizational Commitment & & $R^{2}=.406^{* *}$ & \\
\hline Positive Emotion & -0.05 & 0.15 & -0.42 & Positive Emotion & 0.02 & 0.14 & 0.21 \\
\hline Work Engagement & -0.12 & 0.14 & -1.00 & Work Engagement & 0.33 & 0.13 & $3.39^{* *}$ \\
\hline Coworker Relations & -0.03 & 0.04 & -0.29 & Coworker Relations & 0.35 & 0.04 & $4.59^{* *}$ \\
\hline Meaning & -0.10 & 0.06 & -0.97 & Meaning & 0.06 & 0.06 & 0.70 \\
\hline Accomplishment & -0.10 & 0.11 & -0.71 & Accomplishment & -0.03 & 0.10 & -0.26 \\
\hline Negative Emotion & -0.02 & 0.09 & -0.15 & Negative Emotion & -0.10 & 0.08 & -1.25 \\
\hline Gender & -0.13 & 0.09 & -1.54 & Gender & 0.03 & 0.09 & 0.48 \\
\hline Life Satisfaction & & $R^{2}=.423^{* *}$ & & & & & \\
\hline Positive Emotion & 0.07 & 0.15 & 0.68 & & & & \\
\hline Work Engagement & -0.14 & 0.15 & -1.42 & & & & \\
\hline Coworker Relations & 0.03 & 0.04 & 0.42 & & & & \\
\hline Meaning & 0.46 & 0.06 & $5.53^{* *}$ & & & & \\
\hline Accomplishment & 0.18 & 0.11 & 1.70 & & & & \\
\hline Negative Emotion & -0.20 & 0.09 & $-2.52^{*}$ & & & & \\
\hline Gender & 0.05 & 0.10 & 0.77 & & & & \\
\hline
\end{tabular}

Note: ${ }^{*} p<.05,{ }^{* *} p<.01$. 


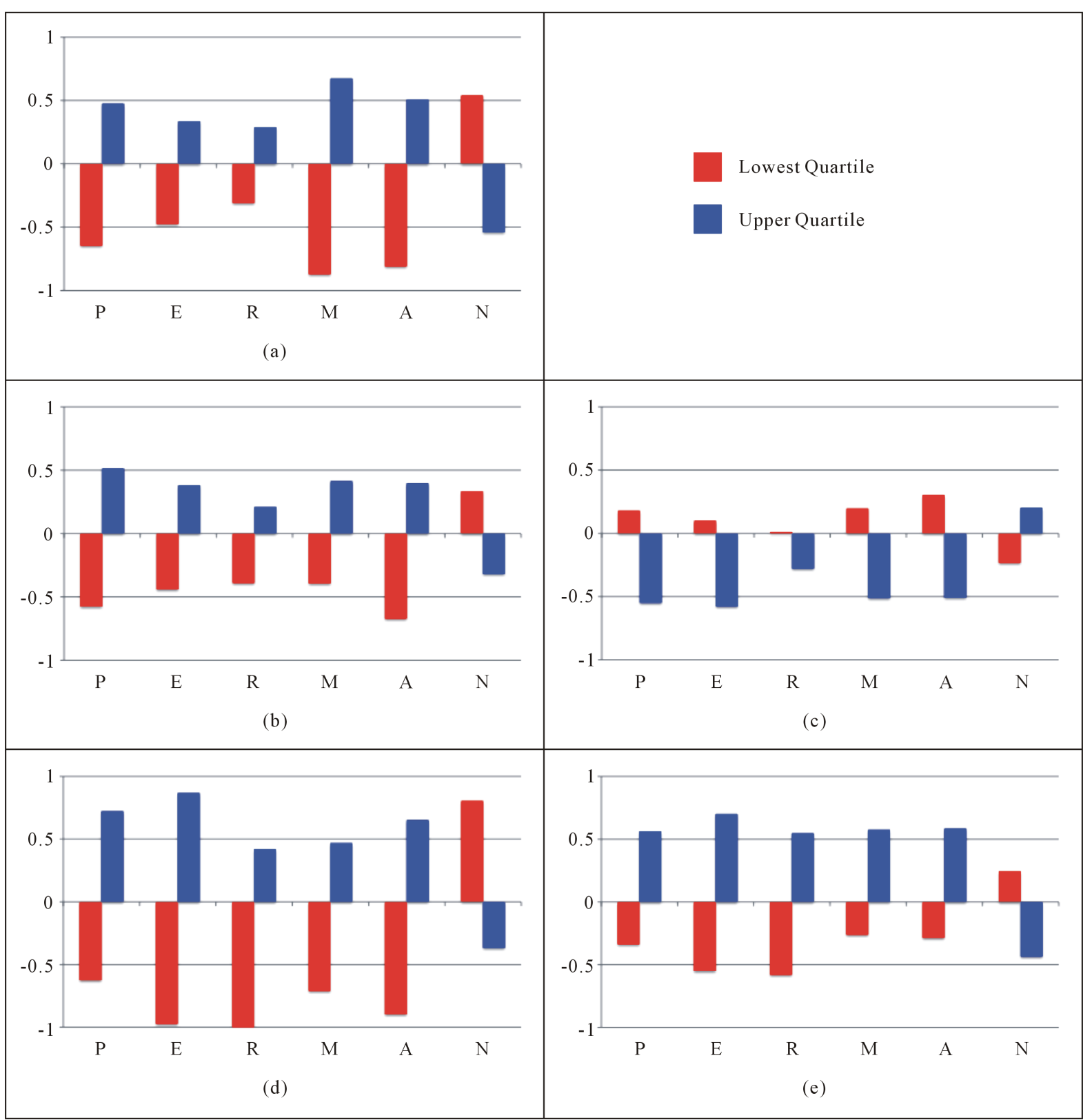

Figure 1. Profiles comparing staff members in the highest versus lowest quartile for each outcome. (a) Life satisfaction; (b) Health/vitality; (c) Somatic symptoms; (d) Job satisfaction; (e) Organizational commitment. Note: Mean values for each scale are $\mathrm{Z}$ scored for comparison. All differences are significant $(p<.05)$. $\mathrm{P}=$ positive emotion, $\mathrm{E}=$ work engagement, $\mathrm{R}=$ coworker relationships, $\mathrm{M}=$ meaning, $\mathrm{A}=$ accomplishment, $\mathrm{N}=$ negative emotion.

quartile for each outcome. Although the high group is clearly higher on each domain (with an inverse pattern for negative emotion), different profiles of PERMA factors distinguish each outcome.

\section{Discussion}

Hoy and Tarter (2011) argue that studying the wellbeing of school staff from a positive psychology perspective will add significantly to the literature, which traditionally has focused more on how to ameliorate negative states (e.g. reducing stress) rather than promote positive states (e.g., increasing PERMA). In this exploratory study, we applied Seligman's (2011) multidimensional wellbeing framework, which directly focuses on the positive side of human function, and examined associations with health, life, and job outcomes. Our approach supports the 
field of Positive Organizational Scholarship, which has become interested in the theory and measurement of employee flourishing (Cameron, 2003).

Using the PERMA framework as our conceptual basis, the results of this study demonstrated that when staff members are doing well across multiple wellbeing domains, they also are more committed to the school, and more satisfied with their health, life, and jobs.

We successfully found evidence for six separate yet correlated factors, and subsequently explored two questions. First, we examined the extent to which positive psychological factors relate to important life outcomes beyond negative affect. Studies have primarily examined associations of negative psychological factors, such as hostility, anxiety, depression, and stress. If wellbeing is simply the lack of these negative psychological factors, then including separate measures of wellbeing is unnecessary. Yet aligned with a growing body of studies (e.g., Boehm \& Kubzansky, in press; Howell et al., 2007), the wellbeing factors predicted health, life, and job outcomes, independently of negative emotion. From the inception of the field, positive psychology theorists have noted that wellbeing is not simply the absence of negative function; our findings add empirical evidence to this claim.

Although growing evidence supports positive associations between wellbeing and physical health, the type of wellbeing may matter, and few studies simultaneously compare multiple aspects (Boehm \& Kubzansky, in press). Our second question asked whether a multidimensional assessment of wellbeing provides more specific information to predict different types of employee outcomes. Positive emotion, meaning, and accomplishment were most strongly related to life satisfaction and health, whereas engagement and relationships related most strongly to job satisfaction and organizational commitment. Although exploratory, our findings begin to build the picture of how different aspects of wellbeing differentially relate to outcomes.

\subsection{Implications}

This is the first study to systematically and empirically apply the multidimensional PERMA model to school staff wellbeing, and to investigate differential associations with self-reported life satisfaction, physical health, job satisfaction, and organizational commitment. There is both theoretical and practical value to measuring and reporting wellbeing as a profile of responses, rather than as a single "overall wellbeing" score. On the theoretical side, modern theories of wellbeing and flourishing are multidimensional in nature, and any composite metric obscures the multidimensionality of both the theories and the measures themselves. Practically, a single wellbeing metric gives little guidance as to how to proceed. If wellbeing is low, we can give various general interventions, which often focus on building temporary positive emotions and reducing negative emotions. In our study, engagement and coworker relationships were the most important variables for predicting professional outcomes such as job satisfaction and commitment to the organization. In contrast, non-work outcomes such as physical health and life satisfaction were more heavily influenced by positive emotion than by engagement and co-worker relationships. Thus, testing the differentiated patterns of a multidimensional scale of wellbeing allows for more tailored approaches to promote wellbeing in school staff.

How can staff wellbeing be supported and cultivated? It is important that school administrators set clear goals that are aligned to the PERMA principles, and then directly incorporate these goals into policies and practices throughout their schools. For instance, training in positive psychology theory and practice can be provided to staff members. A wellbeing interest group that discusses evidence-based articles can be created. Staff meetings can commence by reviewing what is working well in teams and discussing how teams can achieve more. Behavioral codes of conduct can be aligned with wellbeing principles. And returning to the value of a multidimensional assessment of wellbeing, appraisal documentation can include wellbeing measures that document changes and improvements in emotion, engagement, relationships, meaning, and accomplishment over time.

\subsection{Limitations}

Several limitations to the study must be acknowledged. First, we structured our measures and analyses around Seligman's (2011) PERMA model by conducting a factor analysis of the five factors from a series of other wellestablished measures. Additional development work would be needed to fully develop a measure of workplace PERMA. Second, we reported cross-sectional self-reported data. Future assessments will benefit from linking staff reports to objective outcomes, such as health records, absenteeism, and performance. It will be valuable to track wellbeing over time, monitoring changes in wellbeing with different policy or practice changes. Third, the 
sample came from a single school, which was a private boys school in Australia. Future research using the multidimensional approach to staff wellbeing should seek to extend sample sizes and demographics.

\section{Conclusion}

Schools play a critical socialization role in establishing and maintaining positive cultural values both for students and for staff. Teachers are often "measured" by the grades their students achieve. We suggest that the subjective wellbeing of school staff also needs to be an important measure taken by schools. By assessing staff perspectives of wellbeing across multiple domains, there is potential to change the focus and conversation toward wellness promotion for all stakeholders in the education system.

\section{References}

Boehm, J. K., \& Kubzansky, L. D. (in press). Positive Psychological Well-Being and Cardiovascular Disease. In W. Kop, L. Katzel, \& S. Waldstein (Eds.), Cardiovascular Behavioral Medicine. New York: Springer.

Brayfield, A. H., \& Rothe, H. F. (1951). An Index of Job Satisfaction. Journal of Applied Psychology, 35, 307-311. http://dx.doi.org/10.1037/h0055617

Calabrese, R., Hester, M., Friesen, S., \& Burkhalter, K. (2010). Using Appreciative Inquiry to Create a Sustainable Rural School District and Community. International Journal of Educational Management, 24, 250-265. http://dx.doi.org/10.1108/09513541011031592

Cameron, K. S. (2003). Organizational Virtuousness and Performance. In K. S. Cameron, J. Dutton, \& R. E. Quinn (Eds.), Positive Organizational Scholarship (pp. 48-65). San Francisco, CA: Berrett-Koehler.

Cameron, K. S., Mora, C., Leutscher, T., \& Calarco, M. (2011). Effects of Positive Practices on Organizational Effectiveness. The Journal of Applied Behavioral Science, 20, 1-43. http://dx.doi.org/10.1177/0021886310395514

Chan, D. (2011). Burnout and Life Satisfaction: Does Gratitude intervention Make a Difference among Chinese School Teachers in Hong Kong? Educational Psychology: An International Journal of Experimental Educational Psychology, 31, 809-823. http://dx.doi.org/10.1080/01443410.2011.608525

Chaplain, R. P. (2008). Stress and Psychological Distress among Trainee Secondary Teachers in England. Educational Psychology, 28, 195-209. http://dx.doi.org/10.1080/01443410701491858

Cotton, P., \& Hart, P. M. (2003). Occupational Well-Being and Performance: A Review of Organisational Health Research. Australian Psychologist, 38, 118-128. http://dx.doi.org/10.1080/00050060310001707117

Cropanzano, R., \& Wright, T. A. (2001). When a "Happy” Worker Is Really a "Productive” Worker: A Review and Further Refinement of the Happy-Productive Worker Thesis. Consulting Psychology Journal: Practice and Research, 53, $182-199$. http://dx.doi.org/10.1037/1061-4087.53.3.182

Diener, E., \& Chan, M. (2011). Happy People Live Longer: Subjective Wellbeing Contributes to Health and Longevity. Applied Psychology: Health and Wellbeing, 3, 1-43. http://dx.doi.org/10.1111/j.1758-0854.2010.01045.x

Diener, E., Emmons, R. A., Larsen, R. J., \& Griffin, S. (1985) The Satisfaction with Life Scale. Journal of Personality Assessment, 49, 71-75. http://dx.doi.org/10.1207/s15327752jpa4901 13

Duckworth, A. L., Quinn, P. D., \& Seligman, M. E. P. (2009). Positive Predictors of Teacher Effectiveness. Journal of Positive Psychology, 19, 540-547. http://dx.doi.org/10.1080/17439760903157232

Dutton, J. E., \& Sonenshein, S. (2007). Positive Organizational Scholarship. In S. Lopez, \& A. Beauchamps (Eds.), Encyclopedia of positive psychology (Vol. 2, pp. 737-741). Malden, MA: Blackwell.

Forgeard, M. J. C., Jayawickreme, E., Kern, M. L., \& Seligman, M. E. P. (2011). Doing the Right Thing: Measuring Wellbeing for Public Policy. International Journal of Wellbeing, 1, 79-106. http://dx.doi.org/10.5502/ijw.v1i1.15

Gable, S. L., \& Haidt, J. (2005). What (and Why) Is Positive Psychology? Review of General Psychology, 9, 103-110. http://dx.doi.org/10.1037/1089-2680.9.2.103

Howard, S., \& Johnson, B. (2004). Resilient Teachers: Resisting Stress and Burnout. Social Psychology of Education, 7 , 399-420. http://dx.doi.org/10.1007/s11218-004-0975-0

Howell, R. T., Kern, M. L., \& Lyubomirsky, S. (2007). Health Benefits: Meta-Analytically Determining the Impact of Wellbeing on Objective Health Outcomes. Health Psychology Review, 1, 83-136. http://dx.doi.org/10.1080/17437190701492486

Hoy, W. K., \& Tarter, C. J. (2011). Positive Psychology and Educational Administration: An Optimistic Research Agenda. Educational Administration Quarterly, 47, 427-445. http://dx.doi.org/10.1177/0013161X10396930

Hu, L. T., \& Bentler, P. M. (1999). Cutoff Criteria for Fit Indexes in Covariance Structure Analysis: Conventional Criteria 
versus New Alternatives. Structural Equation Modeling, 6, 1-55. http://dx.doi.org/10.1080/10705519909540118

Huppert, F. A., \& So, T. T. C. (2013). Flourishing across Europe: Application of a New Conceptual Framework for Defining Wellbeing. Social Indicators Research, 110, 837-861. http://dx.doi.org/10.1007/s11205-011-9966-7

Judge, T. A., Thoresen, C. J., Bono, J. E., \& Patton, G. K. (2001). The Job Satisfaction-Job Performance Relationship: A Quantitative and Qualitative Review. Psychological Bulletin, 127, 376-407. http://dx.doi.org/10.1037/0033-2909.127.3.376

Keyes, C. L. M. (2002). The Mental Health Continuum: From Languishing to Flourishing in Life. Journal of Health and Social Research, 43, 207-222. http://www.jstor.org/stable/3090197

Kyriacou, C. (2001). Teacher Stress: Directions for Future Research. Educational Review, 53, 27-35. http://dx.doi.org/10.1080/00131910120033628

Lyubomirsky, S., King, L. A., \& Diener, E. (2005) The Benefits of Frequent Positive Affect: Does Happiness Lead to Success? Psychology Bulletin, 131, 803-855. http://dx.doi.org/10.1037/0033-2909.131.6.803

Mowday, R. T., Steers, R. M., \& Porter, L. W. (1979). The Measurement of Organizational Commitment. Journal of Vocational Behavior, 14, 224-247. http://dx.doi.org/10.1016/0001-8791(79)90072-1

Peterson, C., \& Park, N. (2003). Positive Psychology as the Evenhanded Positive Psychologist Views It. Psychological Inquiry, 14, 141-147. http://dx.doi.org/10.1207/S15327965PLI1402_03

Rosseel, Y. (2012). lavaan: An R Package for Structural Equation Modeling. Journal of Statistical Software, 48, 1-36.

Rusk, R. D., \& Water, L. E. (2013). Tracing the size, Reach, Impact, and Breadth of Positive Psychology. The Journal of Positive Psychology, 8, 207-221. http://dx.doi.org/10.1080/17439760.2013.777766

Ryff, C. D., \& Keyes, C. L. M. (1995). The Structure of Psychological Wellbeing Revisited. Journal of Personality and Social Psychology, 69, 719-727. http://dx.doi.org/10.1037/0022-3514.69.4.719

Schaufeli, W. B., Salanova, M., González-Romá, V., \& Bakker, A. B. (2002). The Measurement of Engagement and Burnout: A Confirmative Analytic Approach. Journal of Happiness Studies, 3, 71-92. http://dx.doi.org/10.1023/A:1015630930326

Seligman, M. E. P. (2011). Flourish. New York: Simon \& Schuster.

Steger, M. F. (2012). Experiencing Meaning in Life: Optimal Functioning at the Nexus of Spirituality, Psychopathology, and Wellbeing. In P. T. P Wong (Ed.), The Human Quest for Meaning (2nd ed., pp. 165-184). New York: Routledge.

Steger, M. F., Frazier, P., Oishi, S., \& Kaler, M. (2006) The Meaning in Life Questionnaire: Assessing the Presence of and Search for Meaning in Life. Journal of Counseling Psychology, 53, 80-93. http://dx.doi.org/10.1037/0022-0167.53.1.80

Stiglitz, J., Sen, A., \& Fitoussi, J.-P. (2009). Report by the Commission on the Measurement of Economic Performance and Social Progress. http://www.stiglitz-sen-fitoussi.fr/documents/rapport_anglais.pdf

Velicer, W. F. (1976). Determining the Number of Components from the Matrix of Partial Correlations. Psychometrika, 41, 321-327. http://dx.doi.org/10.1007/BF02293557

Watson, D., Clark, L. A., \& Tellegen, A. (1988). Development and Validation of Brief Measures of Positive and Negative Affect: The PANAS Scales. Journal of Personality and Social Psychology, 54, 1063-1070. http://dx.doi.org/10.1037/0022-3514.54.6.1063

Wright, T. A., \& Cropanzano, R. (2004). The Role of Psychological Wellbeing in Job Performance: A Fresh Look at an Age-Old Quest. Organizational Dynamics, 33, 338-351. http://dx.doi.org/10.1016/j.orgdyn.2004.09.002. 
Appendix: Original Items and Sources

\begin{tabular}{|c|c|c|}
\hline Scale/Item & Response options & Final \\
\hline \multicolumn{3}{|c|}{ Emotion: Positive and Negative Affect Schedule (Watson, Clark, \& Tellegen, 1988) } \\
\hline To what extent do you generally feel this way: Interested & $1=$ never, 5 = always & $\mathrm{P}$ \\
\hline To what extent do you generally feel this way: Distressed & $1=$ never, 5 = always & $\mathrm{N}$ \\
\hline To what extent do you generally feel this way: Excited & $1=$ never, 5 = always & \\
\hline To what extent do you generally feel this way: Upset & $1=$ never, 5 = always & $\mathrm{N}$ \\
\hline To what extent do you generally feel this way: Strong & $1=$ never, 5 = always & \\
\hline To what extent do you generally feel this way: Guilty & 1 = never, 5 = always & \\
\hline To what extent do you generally feel this way: Scared & $1=$ never, 5 = always & $\mathrm{N}$ \\
\hline To what extent do you generally feel this way: Hostile & $1=$ never, 5 = always & \\
\hline To what extent do you generally feel this way: Enthusiastic & $1=$ never, 5 = always & $\mathrm{P}$ \\
\hline To what extent do you generally feel this way: Proud & $1=$ never, 5 = always & \\
\hline To what extent do you generally feel this way: Irritable & $1=$ never, 5 = always & \\
\hline To what extent do you generally feel this way: Alert & 1 = never, 5 = always & $P$ \\
\hline To what extent do you generally feel this way: Ashamed & 1 = never, 5 = always & \\
\hline To what extent do you generally feel this way: Inspired & 1 = never, 5 = always & $\mathrm{P}$ \\
\hline To what extent do you generally feel this way: Nervous & $1=$ never, 5 = always & $\mathrm{N}$ \\
\hline To what extent do you generally feel this way: Determined & $1=$ never, 5 = always & $\mathrm{P}$ \\
\hline To what extent do you generally feel this way: Attentive & $1=$ never, 5 = always & \\
\hline To what extent do you generally feel this way: Jittery & $1=$ never, 5 = always & $\mathrm{N}$ \\
\hline To what extent do you generally feel this way: Active & $1=$ never, 5 = always & $\mathrm{P}$ \\
\hline To what extent do you generally feel this way: Afraid & $1=$ never, 5 = always & $\mathrm{N}$ \\
\hline \multicolumn{3}{|c|}{ Engagement: Ultrecht Work Engagement Scale (Schaufeli, Salanova, González-Romá, \& Bakker, 2002) } \\
\hline When I get up in the morning, I feel like going to work. & 1 = strongly disagree, 4 = strongly agree & E \\
\hline At my work, I feel bursting with energy. & $1=$ strongly disagree, 4 = strongly agree & \\
\hline At my work I always persevere, even when things do not go well. & 1 = strongly disagree, 4 = strongly agree & \\
\hline I can continue working for very long periods at a time. & 1 = strongly disagree, 4 = strongly agree & \\
\hline At my job, I am very resilient, mentally. & 1 = strongly disagree, 4 = strongly agree & \\
\hline At my job I feel strong and vigorous. & 1 = strongly disagree, 4 = strongly agree & $\mathrm{E}$ \\
\hline To me, my job is challenging. & $1=$ strongly disagree, 4 = strongly agree & \\
\hline My job inspires me. & $1=$ strongly disagree, 4 = strongly agree & $\mathrm{E}$ \\
\hline I am enthusiastic about my job. & 1 = strongly disagree, 4 = strongly agree & E \\
\hline I am proud on the work that I do. & 1 = strongly disagree, 4 = strongly agree & $\mathrm{E}$ \\
\hline I find the work that I do full of meaning and purpose. & 1 = strongly disagree, 4 = strongly agree & $\mathrm{E}$ \\
\hline When I am working, I forget everything else around me. & 1 = strongly disagree, 4 = strongly agree & \\
\hline Time flies when I am working. & 1 = strongly disagree, 4 = strongly agree & \\
\hline I get carried away when I am working. & 1 = strongly disagree, 4 = strongly agree & \\
\hline It is difficult to detach myself from my job. & 1 = strongly disagree, 4 = strongly agree & \\
\hline I am immersed in my work. & 1 = strongly disagree, 4 = strongly agree & \\
\hline I feel happy when I am working intensely. & 1 = strongly disagree, 4 = strongly agree & \\
\hline
\end{tabular}




\section{Continued}

Relationships: Organizational Virtuousness Scale (Cameron, Mora, Leutscher, \& Calarco, 2011)

We treat each other with respect.

We trust one another.

We demonstrate integrity.

We foster dignity in each other.

We display confidence in one another.

We show appreciation for one another.

We express gratitude to each other.

We help people who are facing difficulty.

We care for fellow employees who are struggling.

We provide emotional support to each other.

We show compassion for each other.

We build strong interpersonal relationships.

We show kindness to one another.

We honor one another's talents.

We are interested in each other.

We think of each other as friends.

We genuinely care about each other.

We are responsive to each other.

We are being elevated by our work.

We are being renewed by what we do.

We feel that our work has profound meaning.

We find our work motivating.

We see the larger purpose in our work.

We share enthusiasm with one another.

We inspire each other.

We communicate the good we see in one another.

We do not blame one other when mistakes are made.

We correct errors without placing blame.

We forgive mistakes.
$1=$ not at all characteristic; 7 = completely characteristic

$1=$ not at all characteristic; 7 = completely characteristic

$1=$ not at all characteristic; $7=$ completely characteristic

$1=$ not at all characteristic; $7=$ completely characteristic

$1=$ not at all characteristic; $7=$ completely characteristic

$1=$ not at all characteristic; $7=$ completely characteristic

$1=$ not at all characteristic; $7=$ completely characteristic

$1=$ not at all characteristic; $7=$ completely characteristic

$1=$ not at all characteristic; $7=$ completely characteristic

$1=$ not at all characteristic; $7=$ completely characteristic

$1=$ not at all characteristic; $7=$ completely characteristic

$1=$ not at all characteristic; $7=$ completely characteristic

$1=$ not at all characteristic; $7=$ completely characteristic

$1=$ not at all characteristic; 7 = completely characteristic

$1=$ not at all characteristic; $7=$ completely characteristic

$1=$ not at all characteristic; $7=$ completely characteristic

$1=$ not at all characteristic; 7 = completely characteristic

$1=$ not at all characteristic; $7=$ completely characteristic

$1=$ not at all characteristic; $7=$ completely characteristic

$1=$ not at all characteristic; $7=$ completely characteristic

$1=$ not at all characteristic; $7=$ completely characteristic

$1=$ not at all characteristic; $7=$ completely characteristic

$1=$ not at all characteristic; $7=$ completely characteristic

$1=$ not at all characteristic; $7=$ completely characteristic

$1=$ not at all characteristic; $7=$ completely characteristic

$1=$ not at all characteristic; 7 = completely characteristic

$1=$ not at all characteristic; $7=$ completely characteristic

$1=$ not at all characteristic; 7 = completely characteristic

$1=$ not at all characteristic; $7=$ completely characteristic
$\mathrm{R}$

$\mathrm{R}$

$\mathrm{R}$

$\mathrm{R}$

$\mathrm{R}$

$\mathrm{R}$

I understand my life's meaning.

1 = absolutely untrue; 7 = absolutely true

M

1 = absolutely untrue; 7 = absolutely true

M

1 = absolutely untrue; 7 = absolutely true

M

1 = absolutely untrue; 7 = absolutely true

$\mathrm{M}$

My life has no clear purpose.

1 = absolutely untrue; 7 = absolutely true

Accomplishment: Miscellaneous Items

I think I am doing pretty well.

$1=$ not at all, $5=$ very much

I am doing just as well as my peers.

$1=$ not at all, 5 = very much 


\section{Continued}

Even when others want to quit, I know that I can find ways to solve the problem.

I have so much in life to be thankful for.

If I had to list everything that I felt grateful for, it would be a very long list.

I am competent and capable in my daily activities.

Most days I feel a sense of accomplishment from what I do.

How much of the time do you feel you are making progress towards accomplishing your goals?

Most days I feel a sense of accomplishment from what I do.

I am competent and capable in the activities that are important to me.

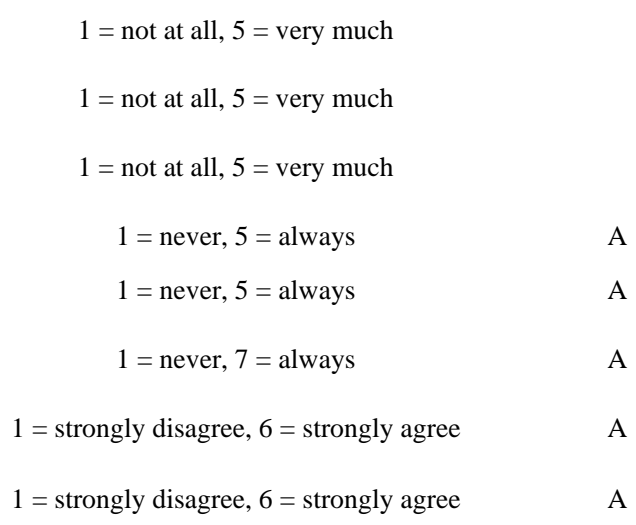

Health and Vitality (miscellaneous items)

In general, how is your health?

Compared to two weeks ago, how do you feel now?

How physically fit do you feel?

How satisfied are you with your current physical health?

How often have you felt rested when you woke up in the morning?

How often have you felt full of energy?

$$
1 \text { = very bad, } 7 \text { = very good }
$$

1 = much worse, 7 = much better

$1=$ not at all; 7 = extremely

$1=$ not at all; $7=$ extremely

$1=$ never, $7=$ always

$1=$ never, 7 = always

\begin{tabular}{|c|c|}
\hline \multicolumn{2}{|c|}{ Somatic Symptoms } \\
\hline In the past two weeks, how often had you had: Cough & $1=$ never, 7 = always \\
\hline $\begin{array}{l}\text { In the past two weeks, how often had you had: } \\
\text { Pain (headache, stomachache, muscle pain) }\end{array}$ & $1=$ never, 7 = always \\
\hline $\begin{array}{l}\text { In the past two weeks, how often had you had: } \\
\text { Chest tightness or trouble breathing }\end{array}$ & $1=$ never, 7 = always \\
\hline $\begin{array}{l}\text { In the past two weeks, how often had you had: } \\
\text { Felt weak, dizzy, or faint }\end{array}$ & $1=$ never, 7 = always \\
\hline $\begin{array}{l}\text { In the past two weeks, how often had you had: } \\
\text { Trouble moving around }\end{array}$ & $1=$ never, 7 = always \\
\hline In the past two weeks, how often had you had: Cold/flu symptoms & $1=$ never, 7 = always \\
\hline $\begin{array}{l}\text { In the past two weeks, how often had you had: } \\
\text { Other health problems }\end{array}$ & $1=$ never, 7 = always \\
\hline
\end{tabular}

Satisfaction with Life Scale (Diener, Emmons, Larsen, \& Griffin, 1985)

In most ways my life is close to my ideal.

The conditions of my life are excellent.

I am satisfied with my life.

So far I have the important things I want in life.

If I could live my life over, I would change almost nothing.
1 = strongly disagree, 5 = strongly agree

1 = strongly disagree, 5 = strongly agree

1 = strongly disagree, 5 = strongly agree

1 = strongly disagree, 5 = strongly agree

1 = strongly disagree, 5 = strongly agree

Index of Job Satisfaction (partial scale; Brayfield \& Rothe, 1951)

I find real enjoyment in my job at St Peter's College

I like my job better than the average person does

Most days I am enthusiastic about my job at St Peter's College

I feel fairly well satisfied with my job at St Peter's College
1 = strongly disagree, 5 = strongly agree

1 = strongly disagree, 5 = strongly agree

1 = strongly disagree, 5 = strongly agree

1 = strongly disagree, 5 = strongly agree 


\section{Continued}

Organizational Commitment Scale (Mowday, Steers, \& Porter, 1979)

I am willing to put in a great deal of effort beyond that normally expected in order to help St Peter's College be successful.

I talk up St Peter's College to my friends as a great School to work for.

I would accept almost any type of job assignment in order to keep working for St Peter's College.

I find that my values and St Peter's College's values are very similar.

I am proud to tell others that I am part of St Peter’s College.

St Peter's College really inspires the very best

in me in the way of job performance.

I am extremely glad that I chose St Peter's College to work for over others I was considering at the time I joined.

I really care about the fate of St Peter's College.

For me, this is the best of all possible school's for which to work.
1 = strongly disagree, 5 = strongly agree

1 = strongly disagree, 5 = strongly agree

1 = strongly disagree, 5 = strongly agree

1 = strongly disagree, 5 = strongly agree

1 = strongly disagree, 5 = strongly agree

1 = strongly disagree, 5 = strongly agree

1 = strongly disagree, 5 = strongly agree

1 = strongly disagree, 5 = strongly agree

1 = strongly disagree, 5 = strongly agree 